\section{Internal Variation in Peach Fruit Firmness}

\author{
Niels O. Maness', Gerald H. Brusewitz ${ }^{2}$, and T. Gregory McCollum ${ }^{3}$ \\ Oklahoma Agricultural Experiment Station, Oklahoma State University, \\ Stillwater, OK 74078
}

Additional index words. Prunus persica, puncture force

Abstract. Variability in mesocarp firmness for peach (Prunus persica L. Batsch) fruit halves cut either parallel or perpendicular to the suture was determined for three cultivars (Halehaven, Ranger, and Topaz). Firmness evaluations were conducted using an Instron Universal testing instrument with a 3.2-mm rounded tip probe. Firmness of the inner, middle, and outer regions of the mesocarp at four angular positions around each peach half was determined at four maturity stages. Average mesocarp firmness declined with advanced stages of fruit maturity. Inner mesocarp was firmest for fruit from all three cultivars. Internal variation in firmness for the middle and outer regions of the mesocarp was highly cultivar dependent. Firmness decreased longitudinally from the stem end to the blossom end and latitudinally from the suture to the cheeks.

Flesh firmness is an important determinant of fruit quality. Mesocarp firmness delineates harvest maturity (Delwiche and Baumgardner, 1985) and directly influences bruise susceptibility (Hung and Prussia, 1989) and postharvest storability (Brusewitz et al., 1992) of peach fruit. Conventional methods for measuring fruit firmness usually involve direct measurement of resistance to puncture or deformation from paired locations of individual fruit, and are reported as the average of these measurements. Although these average firmness determinations reliably reflect many important horticultural characteristics of fruit, they do not necessarily reflect the firmness of localized individual fruit tissues. The internal variation in fruit firmness associated with ripening (Lazan et al., 1989; Pesis et al., 1978) and some ripening disorders (Jackman et al., 1990) may not be reflected in average firmness values.

Changes in firmness occurring during ripening in fruit tissues have been largely attributed to enzymic dissociation of the cell walls between adjacent cells (Fischer and Bennett, 1991; Huber, 1983). In tomato (Lycopersicon esculentum Mill.) fruit, the sequential appearance of polygalacturonase in pericarp tissues during ripening (Tieman and Handa, 1989) correlates well with observed differential softening of these tissues (Hall, 1987). Tissue-specific modification in firmness appears to be a common ripening-as-

Received for publication 18 Nov. 1991. Accepted for publication 27 Mar. 1992. Oklahoma Agricultural Experiment Station journal series no. J6120. Supported by U.S. Dept. of Agriculture grant 8934150-4295 and the Oklahoma Agricultural Experiment Station, Oklahoma State Univ. The cost of publishing this paper was defrayed in part by the payment of page charges. Under postal regulations, this paper therefore must be hereby marked advertisement solely to indicate this fact.

${ }^{1}$ Dept. of Horticulture and Landscape Architecture.

${ }^{2}$ Dept. of Agricultural Engineering.

${ }^{3}$ Current address: Agricultural Research Service, U.S. Dept. of Agriculture, 2120 Camden Road, Orlando, FL 32803. sociated phenomenon in many fruits and vegetables (Hasegawa et al., 1969; Thompson et al., 1982).

Peach fruit cultivars have been characterized on the bases of ease of separation of the mesocarp from the endocarp and flesh texture in mature fruit (clingstone/nonmelting flesh vs. freestone/melting flesh). Ripening clingstone peaches soften considerably less than freestone fruit, and this difference in texture appears to be associated with different molecular forms and quantity of poly galacturonase (Pressey and Avants, 1978). Internal variation, in enzyme concentration or in fruit firmness, has not been determined for peaches. We are interested in the mechanisms involved in peach softening and report here internal variation in texture associated with ripening for three freestone cultivars. The objectives of this study were to determine if softening occurs uniformly around a fruit or progresses from one location to another, and to determine if cultivars differ in their fruitsoftening patterns.

Peach fruit from three cultivars (Halehaven, Ranger, and Topaz) were hand harvested from trees at the Oklahoma Fruit Research Station near Perkins. Peaches were graded into four stages of ripeness (threshold mature to firm-ripe) based on fried L, a, and $\mathrm{b}$ values using tristimulus calorimeter (Minolta CR200, Minolta, Ramsey, N.J.) readings from the greenest portion of the fruit (Delwiche and Baumgardner, 1985). The calorimeter was calibrated with a white reference plate $(\mathrm{Y}=93.7, \mathrm{x}=0.314, \mathrm{y}=$ $0.321)$. Twenty sound peaches representing each ripeness stage for each cultivar were used for firmness measurement.

Firmness evaluations were conducted using an Instron Universal testing instrument (In-
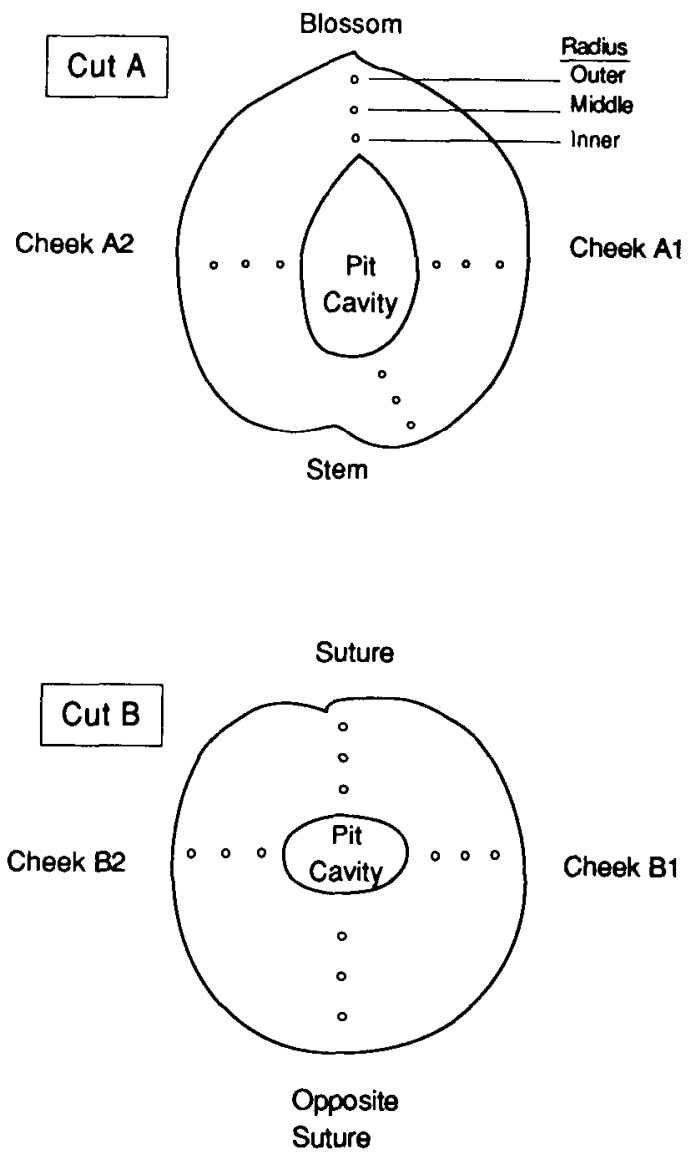

Fig. 1. Instron probe locations for mesocarp firmness evaluations of peach fruit halves. Fruit were cut either parallel (cut A) or perpendicular (cut B) to the suture, and resistance to puncture was determined at four angular positions around each cut face. Resistance to puncture was also determined along the radius at each angular position from the pit cavity toward the pericarp. 


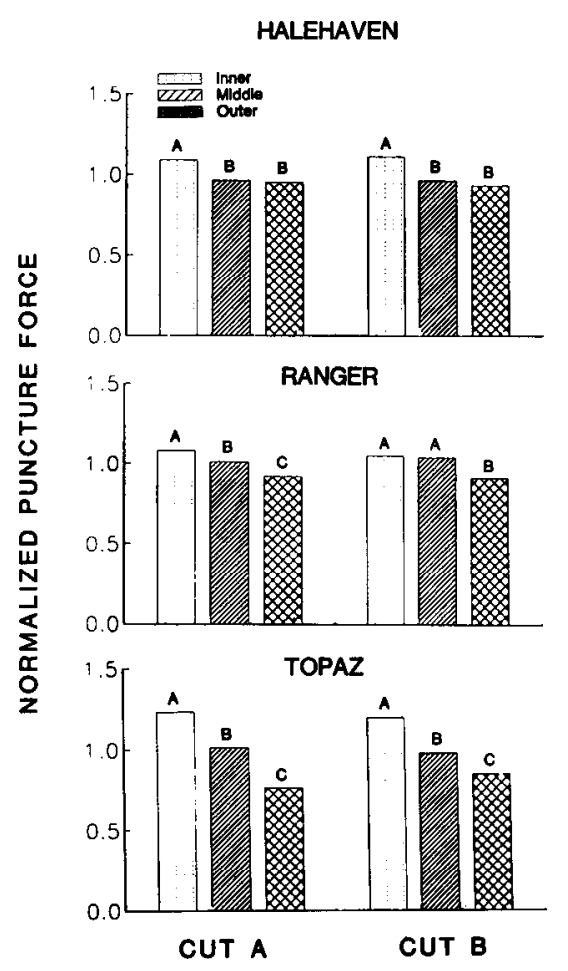

Fig. 2. Normalized mesocarp firmness comparison for the inner, middle, and outer regions of peach fruit halves cut either parallel (cut A) or jected to puncture analysis as depicted in Fig. 1. Bars represent normalized puncture force values over all ripeness stages. Letters above bars are mean separations by Duncan's multiple range test at $P=0.05$.

stron Corp., Canton, Mass.) with a 3.2-mmdiameter rounded-tip probe. The crosshead speed was $10 \mathrm{~mm} \cdot \mathrm{min}^{-1}$, and loads were detected with a 500-N load cell. Data were plotted using a strip chart recorder at $10 \mathrm{~N}$ were used to determine puncture force (maximum force value).

Before puncture testing, 10 of the peaches were cut parallel and 10 perpendicular to the suture (Fig. 1, cuts A and B, respectively). One-half of each peach was then affixed into place for compression tests using floral clay. On each peach face, puncture tests were conducted at four angular positions (Fig. 1)(cut perpendicular (cut B) to the suture, from 'Halehaven', 'Ranger', and 'Topaz'. Fruit were subfull scale. The force vs. deformation graphs

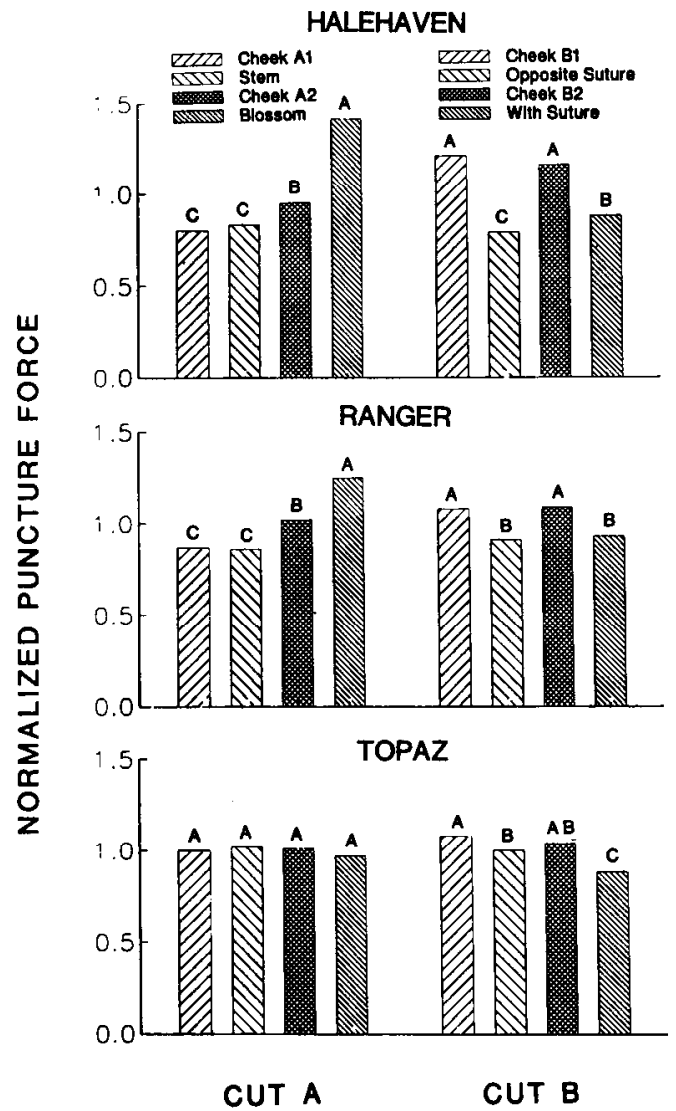

Fig. 3. Normalized mesocarp firmness comparison at different angles around peach fruit from 'Halehaven', 'Ranger', and 'Topaz'. Normalized puncture force values were averaged over maturity stages. Bars for peaches cut parallel to the suture (cut A, Fig. 1) represent values obtained from cheek Al, stem, cheek A2, and blossom locations around the fruit. Bars for peaches cut perpendicular to the suture (cut B, Fig. 1) represent values obtained from cheek B1, opposite of the suture, cheek B2, and at the suture. Letters above bars represent mean separations by Duncan's multiple range test at $P=0.05$.

A, blossom, cheek $\mathrm{Al}$, angled close to the stem end, cheek A2; cut B, suture, cheek B1, opposite suture, cheek B2). At each angular position, puncture tests were conducted at one-fourth, one-half, and threefourths the distance from the endocarp cavity toward the pericarp, resulting in 12 compression tests for each peach half. Puncture tests were always initiated at the midpoint between endocarp cavity and pericarp, and the two subsequent tests of inner or outer mesocarp were randomly assigned.

All cultivars displayed decreasing meso-

Table 1. Average firmness of peach fruit at four ripeness stages for three cultivars.

\begin{tabular}{llcc}
\hline & \multicolumn{3}{c}{ Puncture force $(\mathrm{N})^{\mathbf{x}}$} \\
\cline { 2 - 4 } $\begin{array}{l}\text { Ripeness } \\
\text { stagey }\end{array}$ & \multicolumn{3}{c}{ Cultivar } \\
\cline { 2 - 4 } 1 & Halehaven & Ranger & Topaz \\
\hline 2 & $4.20(0.58) \mathrm{a}^{\mathrm{x}}$ & $3.67(0.88) \mathrm{a}$ & $8.15(0.30) \mathrm{a}$ \\
3 & $1.08(1.10) \mathrm{b}$ & $3.27(0.92) \mathrm{a}$ & $7.51(0.26) \mathrm{b}$ \\
4 & $0.81(1.04) \mathrm{bc}$ & $2.68(1.02) \mathrm{b}$ & $7.22(0.28) \mathrm{b}$ \\
Mean & $0.54(0.93) \mathrm{c}$ & $1.10(1.43) \mathrm{c}$ & $5.73(0.48) \mathrm{c}$ \\
\hline
\end{tabular}

${ }^{2}$ Firmness was determined as the average of puncture force readings $(\mathrm{N})$ taken at 12 locations on two peach halves. Values represent means (SE) from 10 fruit.

${ }^{y}$ Ripeness stages were determined based on fixed L, a and b values obtained from the greenest area of peaches, and range from threshold mature (1) to firm-ripe (4) $(1=$ just reached physiological maturity; 4 = fully mature, some ripening has occurred).

${ }^{x}$ Mean separation within columns by Duncan's multiple range test at $P=0.01$.

"Mean separation within row by Duncan's multiple range test at $P=0.01$. carp firmness with advanced stages of ripeness, and 'Halehaven' was softest, while 'Topaz' was firmest (Table 1). Since one of the objectives of this study was to characterize internal variations in fruit firmness, we needed a method that excluded the large differences among individual fruit. By dividing each of the 12 individual puncture force values by their average, the resulting normalized firmness value was independent of wholefruit firmness but representative of the relative contribution of each puncture to overall mesocarp firmness. Internal differences in normalized mesocarp firmness were detected in 11 of 12 combinations of cut direction, angle, and radius for the cultivars studied (Table 2). Significant differences were detected in normalized firmness between the blossom end, stem end, and cheeks for 'Halehaven' and 'Ranger', but not in 'Topaz' fruit halves.

The inner portion of the mesocarp was firmest in all three cultivars (Fig. 2). Internal regions of the mesocarp was highly cultivar dependent. The middle and outer mesocarp regions for 'Halehaven' fruit were similar in firmness regardless of cut direction, while 'Topaz' fruit were progressively softer from the inner to the outer portions of the mesocarp. Softening was apparently retarded in variation in firmness for the middle and outer 